\section{Levels of Healing A Case of Stomach Cancer}

\author{
Wiet van Helmond, The Netherlands
}

The perfection of our unique art of healing and the welfare of the patients seem to make it worthwhile for the physician to take the trouble necessary to secure the utmost efficiency in his medicines.

Samuel Hahnemann

\section{Introduction}

Every disease, every symptom, is a message from a deeper level. When the message is ignored or suppressed, the body must find a new way to surface the message. And when the ignorance continues long enough we, as homeopaths, are often then confronted with patients who are facing deep pathology.

For us it is always a challenge to bring about a healing, to bend the crisis towards health. Sometimes we can catalyse almost miraculous healing from deep pathological states. Sometimes we are consulted too late - or we simply lose the race against time. Either way, in my experience these are the most exciting cases where we battle to understand the deeper understanding and to bring about some recovery of health. These are the cases I learn most from; they teach me materia medica, pathology, psychology and they bring about spiritual growth. They are also therefore the most frustrating cases.

I would like to share with you a case to reveal my own process and also to show you how beautiful our calling can be. This case will also illustrate that healing may have many meanings and interpretations.

\section{Case of Cancer of the Stomach}

A few years before he actually came to my practice we had met briefly at a social event. We talked about art and homeopathy and he told me he had been battling stomach complaints all his life. Due to the circumstances we couldn't go too deeply into the subject but he told me that when the time was right he would contact me for an appointment. I didn't hear from him for three years.

When he called me he had just heard the diagnosis of stomach cancer. The tumour was growing from the stomach into the oesophagus. There was frequent regurgitation; constant heartburn and stomach pain, difficulty swallowing and he could not lie on his stomach (due to the pains), making it very difficult for him to sleep. He'd become anaemic and even the slightest exercise wore him out. Due to the size of the tumour he had to chew every bit of food extremely well otherwise it couldn't pass into the stomach.

On his chest X-ray there were several spots on his lungs, which may have come from dust (he is an artist and has been working with chemicals all his life) but they might also be metastases. Due to the nature of the complaints I asked him to come that same day. (This shows a frequent mistake I make and I also observe with other homeopaths: we cannot go faster than the pace of the patient in his own process).

\section{Case taking}

He is a 78-year-old male, tall and very thin. He has been doing gymnastics from puberty to his 60th year, which explains his athletic build, but in the last few months he has also lost eight kilograms. His most striking feature is, however, his character. I had noticed this from the first time we met: he is very direct (to the point of bluntness) and the word "grumpy" can only begin to describe his moroseness. If I hadn't met him before I should have thought it was due to his current condition but he says he's always been like this. His wife (who always came with him) and who has known him from early childhood confirmed this.

Because the stomach complaints are old and the diagnosis is recent I receive a lot of medical information that I should like to narrow down so I decide to participate in his directness and I tell him, "I don't think you can get cancer from sitting in a draft."

"So where do you feel this is coming from?" I asked, quite directly.

He immediately looked at me and said that if that were true he could tell me exactly where it came from.

He came from a big family where he was the youngest. All were high achievers except for him. He didn't fit in at school and would much rather be on his own making something than be in class. He had always been artistic and his parents had no idea how to deal with this. He has just always been "the odd one". After he went to an art academy he found it hard to live as an artist. With so many insecurities, life was just much easier if he worked an assignment for an employer. So during his twenties he had several jobs but there was always the inner

\section{S U M M A R Y}

Through a case of advanced stomach cancer I would like to illustrate the different paths of healing. While healing is often defined as the disappearance of pathology, it is, the author suggests seeing healing as learning the lessons that are presented through the symptoms and pathology. Not only is this a more loving perception of health and life but it also doesn't necessarily mean that the pathology has to disappear. In the presented case, while the patient was going through a very profound healing process his pathology remained and even progressed.

KEYWOR DS Cancer, Stomach cancer, Palliative treatment, Chemotherapy, Oesophageal cancer, Metastasis, C4 homeopathy, Baryta phosphorica, Cundurango, Carbo vegetabilis, Cinis ligni, Arsenicum album, Emerald immersion, Thuja, Kübler-Ross, Death, Dying, End stage treatment 
conflict of wanting to be creative and to make everything according to his standard of perfection and according to his own creative impulses, or to have the safety of a steady income, less responsibility and work on assignments. And he always feared responsibility. If his bosses gave him carte blanche on a project he would freeze. If the workload became too much and an extra hand was hired and placed under his command, he would freeze. His work was always highly praised but sooner or later the working situation would always become impossible because the more appreciation he got, the more morose he became, because he only did fifty percent of the total work. None of the praise really touched him and he would become more and more irritable from it. The directness that followed from this didn't help. Whenever something wasn't up to his standards (which are extremely high) he would speak bluntly to his boss's face. But if his boss then said, "Okay, the next project you can do on your own" he would get into an inner panic of what to do and where to start and most of all the feeling of "I can't do this!"

So over the years he had several jobs that he always left with some form of conflict, until he was discovered by another artist who was working on a large project consisting of many works and who greatly admired his tremendous passion for materials and his ability to realise things. This became the beginning of a beautiful friendship. Everything his colleague drew or painted he could bring into the real world. He loved this job; "I really found my place in the world." For years they would work overtime until late at night because they had so much fun in the creational process. Yet even though their combined work drew millions of people every year there was always the inner conflict that kept on nagging: What can I do on my own? What can I create from scratch? Highly content with his work he was frequently given the chance to do this but he always declined. Something inside blocked and he panicked. He was always afraid of the responsibility. The result was, however, that whenever one of the fruits of his labour was mentioned, his name was never mentioned. During these years his stomach problems arose.

So I ask him: "What lies behind this fear of responsibility? What causes the panic?"

"It has to do with an insecurity but I cannot define it. I have thought and talked about it often. When I'm working I can have a thou- sand people look over my shoulder, I don't care in the least. I'm not insecure about what I do as long as I am doing it. When it is finished that's another story. The insecurity is about myself and when the entire production is in my hands, when I have to delegate work and carry all responsibility I get panicked. And not just a little. I become hectic and nothing creative happens. And this is a very old pattern. My wife and I have been together for over 40 years but we only married about eleven years ago. I proposed earlier, and we even had a date set. But on the day of the wedding I got so scared; was I really the right man for her? It was the same sort of panic and my wife called it all off because she was afraid I wouldn't live through the day. It was horrible.

My favourite artist is Rodin. Not only was he a great sculptor but also he was so creative that he would start the project and then one of his assistants would finish it. Of course nobody knows the assistant. Now I'm not saying I'm Rodin but I have this tremendous desire to do my work but who knows me?"

\section{Miscellaneous information \\ - Appendicitis at seven \\ - Abdominal aneurysm three years ago \\ - Aneurysm in head five years ago \\ - Anaemic periods since childhood \\ - Always cold \\ - Nervous cough \\ - Tonsillectomy as a child}

\section{What to do, what to do?}

At moments like this I feel a bit anxious as well. Whatever I'm about to do, I have to do it well: I feel I must choose the right remedy, the right potency, the right time. The biggest lesson I've learned from such situations is that I shouldn't rush, but rather take my time to consider the case. Don't yield to temptation with a quick prescription, I say to myself. Wait a bit; sleep on it. Don't start analysing immediately; don't even think about rubrics or remedies. Just let it all sink in and abstract the essence. What needs to be cured? What needs healing?

His appearance to me was of good vitality. But it is not rare that during a metastasis process there appears to be an increase in vitality [2], when the body finds a new energetic equilibrium through the metastasis.

It seemed that he knew quite well what was behind the cancer. Incidentally Ryke Geerd Hamer [1] says that oesophageal and gastric tumours can come from the inability to process something or being unable to process a certain anger or frustration. So it all makes sense thus creating the next question: in my prescription how much do I emphasise the anger and frustration or the insecurity and panic? I figured that the anger was the natural consequence of the panic. Doesn't everybody have the desire to bring into expression every aspect of himself? Aren't we all frustrated when what we wanted isn't what we got?

\section{Treatment}

I decided to prescribe Baryta phosphorica MK $[5,6]$ a week later followed by a daily plussed dosage of Marsdenia cundurango C30 (Banerji: “...tannins of Cundurango can initiate apoptotic mechanisms in the tumour cells and thereby produce a regression in the tumour. Thus our findings indicate that Cundurango is a medicine that can be used with reasonable confidence in the treatment of oesophageal carcinoma.") $[3,4]$.

With his grumpiness our attention isn't drawn to any Phosphorus remedy. But I have seen a lot of people who were Phosphorus-like (open and friendly) in a previous state that became very morose in later stages. However he was grumpy as long as he could remember...

While talking about hobbies he mentioned that part of his love of gymnastics was that it was a very easy way to meet new people. He would help organise events and train other gymnasts. And then he would be very much the Phosphoric type we all know. But the most important is why Baryta phosphorica? I chose this remedy because of his anxious reaction towards what he calls responsibility. He has taken on a very sensitive attitude to the wants of the other because he knows exactly what the other person/artist wants and can make it into reality. Even the simplest sketch will inspire him to bring to material realisation the essence of the artist's vision. This capacity was how he explained the success of his long-term collaboration with the other artist. He feels he cannot express his own creativity completely independent of another. So he is dependent and he would need to feel the need of the other artist tremendously well in order to function (create art) on his level of professionalism. The barium element of course fits the gastric cancer, difficulty swallowing, dependence, insecurity and history of aneurysms and tonsillitis. 
Rubrics in random order

- MIND - HIDING - himself

- CHEST - ANEURYSM of

- GENERALS - ANEURYSM

- MIND - ACTIVITY - desires activity creative activity

- MIND - ART - ability for

- MIND - COMPANY - desire for

- MIND - CONFIDENCE - want of selfconfidence - self-depreciation

- MIND - DELUSIONS - succeed, he does everything wrong; he cannot

- MIND - DEPENDENT of others

- MIND - FEAR - undertaking anything; of

- MIND - IDEAS - abundant

- MIND - MOROSE

- STOMACH - CANCER

- THROAT - SWALLOWING - difficult

For the last couple of years I've been using the Banerji Cancer Protocol [4] a method of using low potency organ directed remedies with many of my cancer patients. In the case of oesophageal cancer the protocol suggests the Cundurango plant (sometimes written as Condurango) from the Asclepiadaceae family of which Jan Scholten [7] says that they look like the Silver series: they want to achieve a lot and they want success. In Ecuador the Cundurango plant was used to treat stomach cancer and syphilis and recent research shows it has very strong antibacterial effects in treating tuberculosis $[8,9]$ (which gives you an idea as to its miasmatic field of effect).

\section{Follow-up}

Because his oncologist advised him to start chemotherapy (carboplatin in combination with paclitaxel) as soon as possible we planned a consult two days before his first chemotherapy.

He says he feels relatively well. Energy is up and swallowing has become much easier. Further research has shown that the lungs have several metastases as well as a metastasis in an axillary lymph node and two in the oesophagus. He feels really angry about why this was discovered so late. He has been taking Nexium (esomeprazole to block the production of acids in the stomach) for years and he has an annual stomach check-up to prevent this from happening. "I was told to keep my mouth shut and be polite. But why!"

"I'm tired from always fighting. Even as a child I was often tired. As a five-year-old I would escape my mother's attention and go take a nap somewhere in the house. She always told me I was a lazy bum. I'm always fighting with myself. I'm so discontented with myself. I feel everybody can do something better than me. I cannot accept that I'm like that. Sure, I have a very clear opinion about things. I was never insecure about that. But as for what I can do... I'm never satisfied. It took me almost twenty years to build my own house. I wanted everything to be perfect so I had to do everything myself. It's still not finished. While I am building I can be very content. It all has to be to my standard of perfection and when it's up to that it's okay. But then when everything is finished the doubt and discontent start."

Because we are only two days before chemotherapy starts and it is very natural to be in an anger stage (Kübler-Ross stage 2) I decide it is better to wait.

The next months I can barely keep up with the side effects of the chemotherapy. I manage to alleviate his nausea and vomiting with Ipecacuanha C 30 and for the first two weeks Cinis ligni. [A remedy made from wood ashes, which has similarities with Carbo vegetabilis, and about which Withold Ehrler [11] says: "This is the remedy for people who are voluntarily fighting a losing battle." C4/10 gives him a bit more energy but after that it doesn't help anymore and I need to switch to Carbo vegetabilis (C6, C12 and (30), which to some degree continues to work throughout the next six months of treatment.]

\section{Rubrics in random order}

- GENERALS - CACHEXIA - cancer; from

- GENERALS - WEAKNESS - cancer; in

- STOMACH - CANCER

Of course it would be nice if nothing intervened with the workings of Baryta phosphorica but this is real life and people are put under a lot of pressure by oncologists. A lot of pressure! Besides the knowledge of having cancer his oncologist told him he would die if he did nothing (true: a life expectancy of more than five years in stage four stomach cancer is very rare [13]). However he wasn't told that the life expectancy if treated was about the same. Only in the best-case scenario he would have a bit more time and less complaints than the primal expectation. So treatment is palliative: you try to slow down the growth and with any luck even shrink the present tumours but the process is irreversible. Under this pressure he agreed to take a cocktail of chemotherapy.
So whether or not Baryta worked is not completely clear. What was clear was that he got closer to his core feelings. He allowed people to come closer to him, take up more space. But I will leave it to the reader to interpret.

After the third chemo his leucocyte and erythrocyte count dropped to the point where the treatment had to be stopped and he was taken to the hospital where he got a blood transfusion. This didn't achieve the desired effect and so far the chemo results were also meagre. The primary tumour had shrunk a few millimetres but the oncologist wasn't pleased and asked them to reconsider treatment because the tumours were about the same and the body was drained of energy. However he still wasn't told about the prognosis of the therapy and because he still wanted to fight, the oncologist suggested stopping the treatment and changing to radiation therapy. He slowly started to feel that the disease was going to get the better of him but he still wanted the extra time to finish his affairs. He wasn't ready yet. Even worse, over the last months so much energy was spent fighting the disease that the message behind it seemed lost.

For me this was the hardest part because I had to let him be. He's my patient and it is his life. All I could do was steer him back to the essential problem and in the meantime let him thrash about. It's all part of the process. His and mine.

Happily the Cundurango effect was very clear. If he accidentally forgot his daily dose his stomach symptoms returned immediately, so we continued using the remedy. I felt it wasn't going deep enough; it was only soothing, and so asked him to come to the practice to discuss the next step. This time I wanted to give him something prior to the next allopathic treatment, radiation.

We talked about his work, his colleagues, his youth, his anxieties and what was happening now. Running through all events was the way he looked at himself. When he was in the hospital he was amazed that people came to visit him. He with all his bad moods, his moroseness it just didn't add up. He felt completely unlovable and yet here were all these people. It was flattering in a way but it still didn't connect on a deeper level. He felt the same disconnection in his work. Millions of people appreciated his works but because they weren't solely his he couldn't feel the appreciation 
in the slightest. This was also what was happening in his marriage and past relationships. Constantly feeling he was unlovable he could never allow himself to feel loved. In the 40 years he and his wife knew each other he never even told her. In a way he felt loved but if she said she loved him he couldn't feel it. This created a tremendous feeling of loneliness, of always being cut off from the outside world and its inhabitants. Leaving him more and more embittered, grumpy.

My first thought was Pseudotsuga menziesii (the Douglas fir [12]). Like Thuja it is also from the conifer family. There are some resemblances but the unique aspect of this remedy is their inability to create or enjoy intimacy. It's the phrase "together alone." They are disconnected from this source, thus feeling isolated. With each negative experience they become more morose, more critical because they are unable to connect to the outside world in this way. They do not feel the love or emotional charge coming their way and this feeds their moroseness. They become more and more direct and antisocial in their reactions to the outside world. But inside they feel the loss, the grief. They become very critical of themselves and to others. I interpret this as being like a child in puberty, constantly seeing how far he can go in order to feel a certain boundary. They want this emotional connection, this intimate feedback and because they cannot feel it they "up the volume" of their expressions.

But because of the frailty of the situation I slept on it and chose Thuja C4/40. My preference for the $\mathrm{C} 4$ trituration was because his problem was in essence a $C 4$ problem: "Why is this happening to me? What is the lesson in it? What is, beyond all physical discomfort, the spiritual gift of this disease?" Depending on the level of the functioning of the patient I prescribe from a different trituration level. In the C 4 our questions have to do with self-acceptance, looking into our own shadow. Looking at ourselves without judgement. This to me seemed to be what he was doing.

\section{Rubrics in random order}

- MIND - CONFIDENCE - want of selfconfidence - self-depreciation

- MIND - CONSCIENTIOUS about trifles

- MIND - DELUSIONS - appreciated, she is not

- MIND - MOROSE

- MIND - REPROACHING oneself

- STOMACH - CANCER
- MIND - SENSITIVE - sensual impressions, to (I feel this rubric comes closest to his symbiotic ability to feel what other people/artists were in need of and then being able to create it)

His reaction was wonderful. He started calling people to come and visit him: called old colleagues to talk about past projects, and people he had avoided before because they confronted him with his deeper feelings of not being good enough, not being the sole creator of projects. Now he talked to them and they had the most uplifting conversations. At one point he called me late in the evening and told me he just had his old colleague over for dinner. He told this colleague that he had always admired him for his ability to really create art, that he always looked up to him for this. The colleague laughed and told him he had always been jealous of him because of his mastery over the materials; that he had always felt inferior and dependent on him because of this. They talked about it all night, and it felt as if a weight had been lifted.

In his relationship with his wife he started saying he loved her. Not because he wanted to hear it back from her but because he really felt it, deeper and more sincerely than before.

When a friend promised to visit him at the hospital but didn't arrive he cried. For the first time in his adult life he started to cry. When he was happy, disappointed or just sad he cried and was not ashamed to show it. At the age of 78 with a lifelong build-up of grumpiness he completely transformed.

Then the radiation therapy started and while we all hoped for further relief and extra time there was an adverse effect. Where there should have been pain relief from the decay of cancerous tissue the radiation caused almost unbearable pain. They almost immediately decided to stop the treatment but the aftereffects of the radiation developed in the following days and the pains became progressively worse. The obvious remedies (Calendula, X-ray, Radium bromatum) were ineffective. Within a week he went from a combative stand to complete defeat. He wanted to die and the sooner the better. Eating, drinking, breathing, sleeping, sitting, lying, everything had become excruciating painful and he had been unable to leave the hospital for over a week.

Although welcoming death he knew he still wasn't ready. The message was still not completely heard, not completely processed. He still kept saying he was fighting so much with himself. There was no inner peace yet and as long as he hadn't achieved it he refused morphine for fear of clouding his mind. Again a fight within himself.

When somebody comes to you in such a state (and the ground had really caved beneath his feet), you really want to help. I really wanted to give the most perfect remedy for the moment. At least that's what I felt. He was fighting the war on so many fronts that nothing positive was coming out except for the cancer's slow progress. Again I had to sit on my hands and really think it over. What needed healing? Of course I could have repeated Thuja but it didn't feel right. The feeling of disconnection was lifted and his current state didn't point to Thuja. I now needed something else for him but what? What was it that I wanted for him? It would have been so easy to join him in his battle and fight his body's messages. But I didn't want to. After considering several remedies I gave him Peter Tumminello's Emerald immersion C30 $[14,15]$.

In situations like these I am seldom tempted to reach for "new" remedies. Initially I often set my Radar [16] to the 1916 Kent edition in such cases to keep my eyes on the well-worn path. But in this case the worn path did not bring me the answers I sought. And Emerald fit very nicely.

\section{Emerald}

According to Peter Tumminello Emerald "is the gem of guidance on the journey of undertaking great tasks and is indicated when one feels that their potential and desire for expression is trapped and needs release. This is often associated with frustration and anger." [17]

The Emerald also has Pseudotsuga's problem of being unable to communicate on the emotional level. The patient feels his potential and desire for expression (which creates intimacy) but is trapped, disconnected from this way of communicating which often leads to frustration and anger, from one's own incapacity. Madeline Evans says it will make the patient speak the truth but also brings peace, harmony and love into the being. It is for people who misinterpret what is said because their anger and bitterness block their perception. It will heal this trauma to the heart chakra and reconnect with the spark of life. In this way it is also very similar to remedies like Natrum 
muriaticum. There is an emotional wound after which the emotional becomes hardened or even disconnected. In this aspect it is also strongly linked to Thuja, Sequoia and in my opinion to the Pseudotsuga.

In her 2008 lecture on Emerald, Alize Timmerman [20] confirmed Peter Tumminello's finding that this is a remedy for balancing the male and female when the patient is stuck in the masculine energy (other gemstones like the moonstone are also very similar in this way).

Besides Tumminello's proving there are also other Emerald provings by Ross and Campbell [18] and Madeline Evans [19]. All of them concur with this theme in one way or another and these latter authors also mention the important use of this remedy in cancer and radiation problems. So, like his Cundurango (which he was still taking) I had found another remedy that covered both his current state as well as his underlying problem.

\section{Reaction}

The effect was beyond expectation. The pain subsided to a bearable level within hours after taking the remedy and his mind came to rest enabling him to set his priorities, go back to his essence and feel what needed to heal. I decided to use the plussing method [3] with the Emerald to see where it would take him.

The next day after taking the remedy he was dismissed from the hospital and he didn't return there. (To my great amusement the oncologist who had been treating him for about a year called me after that prescription because he had never seen such reactions. He didn't understand why for the past eight months his patient hadn't been in agonizing pain. The size and amount of tumours should have given many more problems. He even expected him to have died months ago. He wanted to know what I had given him and where he could get these remedies).

For the next three months he just enjoyed life. He worked in his garden, worked on some artwork, went on a holiday with his wife, celebrated his 79th birthday, ate and drank his favourite foods, but most of all really came to peace with himself.

The last time he came to the practice he was a new man. He told me he never knew he was so loved by people. He laughed and cried about it. There was no anger or bitter- ness about what had happened, or regret that he had only come to this point in his last few months. He could accept the situation completely and therefore he could live in the moment and be happy. There was no fear of death, cancer or living. There was only life.

In my opinion this is the healthiest state we can be, living life from the $\mathrm{C} 4$. He was no longer judging himself. He was able to shed his repulsive moods and felt at peace with his physical state. This to me is really living from your deepest self.

Although in the eye of the storm, he was truly happy. And we left it at that.

Two weeks later he called me in the evening. Within the last 24 hours he had gained over five kilos, he was weak, he couldn't sleep or eat, and he had not passed stools or urine in the last 24 hours. It was time.

The next day on my way over to his house I found myself smiling as I reflected the last couple of months we shared. "Who has been guiding whom?" I wondered.

When I arrived he was lying on a bed in the living room. While he was very calm in the days before the tumour had spread to his kidneys, with the sudden physical changes he had become restless. He hadn't slept in over 48 hours, his eyes were darting in their sockets, and his movements jerky; he was very tired and anxious and could not surrender to sleep.

Just before I arrived his GP had been there for a visit and had offered him Midazolam (dormicum). He told him with this medication he would just go to sleep and ease into death. He laughed and told the doctor "Well now doctor, that's a bit drastic isn't it?" He preferred to wait for me.

But in this restless state his mind couldn't maintain its inner calm and his religious upbringing was bubbling up. "It's a battlefield again inside. What if I have to answer to God for all my mistakes, for not changing earlier, for not listening to my body earlier? Maybe for not treating people better?" He was really troubled by these thoughts and this was also keeping him awake. I told him that if he had to give over responsibility for his actions to God, wouldn't God probably also know about the millions of people every year who enjoy his work? Wouldn't this logically cross out one against the other? He laughed and hugged me.

I ask him "What if I were to give you a remedy that would bring you calm without clouding your mind? Then you could say goodbye to your wife and just go. Would you take that remedy?" He accepted and give him Arsenicum album C30. I said my goodbyes and I left him with his wife. She told me that he became very calm within a few minutes, that they talked for a quarter of an hour and then he fell asleep.

\section{Again rubrics in random order \\ - GENERALS - EUTHANASIA; to induce \\ - MIND - SELF-CONTROL - increased \\ - SLEEP - SLEEPLESSNESS - restlessness, from \\ - MIND - DELUSIONS - die - about to die; one was}

\section{Conclusion}

If we look at this case from a C3 level (the mental level) we can frustrate ourselves because of the life lost, the disease incurable. But to me it was a very successful case and a beautiful example of C 4 homeopathy. In the medical profession it is very easy to think dualistically. If there is pathology we should treat it. True but we shouldn't lose track of what caused the pathology. It is very easy to open our repertories and find a rubric for stomach cancer and then pick the most likely remedy. After that we think of that patient as a "Thuja" or a "Baryta" patient and lose contact with the deeper cause and the gift that every disease can be. And thus it is just as easy to suppress or aggravate a complaint. In my opinion we must always ask our patients and ourselves what needs to be healed? And if we are able to touch that place within our homeopathic principles we can have the most wonderful results. I am reminded of Elisabeth KüblerRoss' quote:

"People are like stained-glass windows. They sparkle and shine when the sun is out, but when the darkness sets in their true beauty is revealed only if there is light from within."

It is so easy to push and pull with homeopathic remedies because of our own fear and insecurities. But if we connect with our own C4 level, and look to our patients without judgment, we can have much better results. 


\section{References}

${ }^{1}$ Hamer RG. Cancer and Hypnosis. Online: http://hypnosisforcancer.net [accessed May 2, 2012]

2 Timmerman A. Seminar on the Homeopathic Treatment of Cancer, Novato, California, Oct. 2007

${ }^{3}$ Ramakrishnan AU, Coulter CR. A homeopathic Approach to Cancer. Arlington, US: Ninth House Publ.; 2002

4 The Banerji Protocol - A New Horizon in Medicine, by Prasanta \& Pratip Banerji of The PBH Research Foundation, India; 2007

5 Scholten J. Homeopathie en Mineralen. Utrecht, Netherlands: Alonnissos; 1999

${ }^{6}$ Sankaran R. Soul of Remedies. Bombay: Homoeopathic Medical Publishers; 1997

7 Scholten J. Seminar, “Creating Space”, Utrecht, Netherlands, May 2009

${ }^{8}$ Grange JM et al. Detection of anti-tuberculous activity in plant extracts. J Appl Bacteriol 1990; 68: 587-591

9 Tropical Plant Database. Condurango. Online: http://www.raintree.com/ condurango.htm [accessed August 11, 2011]

10 Online: http://en.wikipedia.org/wiki/Kübler-Ross_model [accessed May 2, 2012]

${ }^{11}$ Ehrler W. Perlen der Pharmacognosie. Freiburg: Held Verlag; 2000

12 Olson S. Arbor Materia Medica Volume 1. Maple Ridge, Canada: Legacy Publications Inc.; 1997

13 Online: http://en.wikipedia.org/wiki/Stomach_cancer [accessed August 11, 2011]

14 Tumminello P. Twelve Jewels. The medicine Way. St Leonards, Australia: The Medicine Way; 2005

15 Tumminello P. Lecture, Hahnemann Institute, The Hague, Netherlands, 24. - 26.4.2009

${ }^{16}$ Software Radar 10.5. Assesse (BE): Archibel; 2009

17 Tumminello P. Introduction to the Gem Family. Kandern (DE): Narayana Verlag; 2011

18 Ross M, Campbell S. The homeopathic and Meditative Proving of Emerald. Tunbridge Wells (UK): Helios Homoeopathy Ltd.; 2001

${ }^{19}$ Evans M. Meditative Provings, Volume 1. 2nd ed. York, UK: The Rose Press; 2005

20 Timmerman A. Seminar on Gemstones, 2008

\section{Vita}

Wiet van Helmond is a Dutch homeopath practicing in the Dutch cities of Vught, Heusden and The Hague. Besides his practice he is one of the teachers at the Hahnemann Instituut and The Academy for Natural Healing. Since 1999 he has been studying C4 homeopathy and has been part of over 20 triturations and provings.

Wiet van Helmond

Vlasmeersestraat 76

5261 TD Vught

The Netherlands

E-mail: wiet@c4-homeopathy.com 